\title{
Örgüt İklimi Algısı ve Yenilikçi İş Davranışı İlişkisinde Bilgi Paylaşımının Aracılık Rolü Üzerine Ampirik Bir Çalışma
}

DOI: 10.26466/opus.594768

\author{
Sema Yiğit* - Alperen M. Yiğit** \\ * Doç. Dr., Ordu Üniversitesi, Ünye İ.İ.B.F., Ünye/Ordu/Türkiye \\ E-Posta: semayigit@yahoo.com \\ ORCID: 0000-0003-4497-7529 \\ ** Dr. Öğr. Üyesi, Ordu Üniversitesi, Ünye İ.İ.B.F., Ünye/Ordu/Türkiye \\ E-Posta: yigitalperen@hotmail.com \\ ORCID: 0000-0002-4141-2621
}

$\ddot{O} z$

Yenilikçi olmak her örgüt için rekabet gücü kazanma yolunda zorunluluk haline gelmiştir. Örgütlerin yenilikçi olması ise çalışanların yenilikçi iş davranışları göstermesi ile mümkündür. Çalışanları bu davranışları göstermeye sevk eden çeşitli bireysel ve örgütsel faktörler vardır. Bu çalışma kapsamında söz konusu faktörlerden örgüt iklimi algısı ve bilgi paylaşımı ele alınmıştır. Illgili literatür incelenerek bu iki faktörün yenilikçi iş davranışı ile ilişkisi ortaya konmuş ve çalışmanın temelini bu ilişki ağ̆ oluşturmuştur. Çalışmanın amacı çalışanların örgüt iklimi algısı ile yenilikçi iş davranışları arasındaki ilişkiyi incelemek ve bu ilişkiye bilgi paylaşımının aracılık edip etmediğini ortaya koymaktır. Çalışma amacına uygun olarak anket yöntemiyle elde edilen veriler, kalkınma ajanslarındaki çalışanlardan elde edilmiştir. Toplanan verilere öncelikle geçerlilik ve güvenilirlik analizleri yapılmıştır. İlgili literatür taraması sonucu oluşturulan hipotezler SPSS ve AMOS programları yardımıyla test edilmiştir. Elde edilen bulgular neticesinde çalışanların örgüt iklimi algısının yenilikçi iş davranışı üzerinde anlamlı bir etkisinin olduğu ve bilgi paylaşımının bu etkide kısmi aracılık rolü oynadığı görülmüştür.

Anahtar Kelimeler: Örgüt İklimi Algısı, Bilgi Paylaşımı, Yenilikçi İş Davranışı 


\title{
An Empirical Study on the Mediating Effect of Knowledge Sharing on the Relationship between Organizational Climate Perception and Innovative Work Behavior
}

\begin{abstract}
Being innovative has become a necessity for every organization to gain competitiveness. Organizations can be innovative by way of employees who have innovative work behavior. There are various individual and organizational factors that encourage employees to demonstrate these behaviors. In this study, "organizational climate perception" and "knowledge sharing" among these factors are discussed. The relationship between these two factors and innovative work behavior was revealed by examining the related literature and the basis of this study was formed by this relationship network. The aim of study is to examine the relationship between perceived organizational climate and innovative work behavior and to determine whether the employee knowledge sharing mediates this relationship. In accordance with the purpose of the study, the data obtained by survey method were obtained from the employees of development agencies. Firstly, validity and reliability analyses were performed. The hypotheses generated by the relevant literature review were tested with the help of SPSS and AMOS programs. As a result of the findings, it was seen that organizational climate perception had a significant effect on innovative work behavior and employees' knowledge sharing played a partial mediator role in this effect.
\end{abstract}

Keywords: Organizational Climate Perception, Knowledge Sharing, Innovative Work Behavior 


\section{Giriş}

Günümüzün bilgi yoğun ekonomisinde, bir örgütün mevcut bilgisi ve bu bilgiyi yenilik faaliyetlerinde kullanma yetisi giderek daha önemli bir kaynak haline gelmektedir. Yenilikçi çalışanlar bu noktada önemli roller üstlenirler. Bu çalışanlar bilgi edinmeye dair motivasyona ve kabiliyete sahip olup örgütü yenilik yapmaya taşıyan temeli inşa ederler. Ancak bireysel bilginin örgütsel bilgi haline gelmesi örgütteki yenilik faaliyetleri için oldukça önemlidir. Bu noktada öne çıkan bilgi paylaşımı hem bilgi alışverişi sağlayarak yeni bilgi edinimini kolaylaştırmasına hem de bireysel bilginin örgütsel bilgi haline gelerek bilginin bir nevi kurumsal bir kimlik kazanmasına yardım eder. Bu bağlamda bir örgütte yenilikçi iş davranışına sahip çalışanların olması önemli iken bu çalışanların bilgi paylaşımında bulunması da ayrı bir öneme sahip olacaktır.

Örgüt seviyesinde inovasyon faaliyetlerini gerçekleştirmek için çalışan seviyesinde yenilikçi olma gerekliliği göz önünde bulundurulduğunda, araştırmacılar arasında çalışanların hangi sebeplerle ve hangi şartlar altında yenilikçi davranış göstereceğine dair büyüyen bir ilgi vardır (Sanders ve Lin, 2016, s. 33). Yine benzer şekilde çalışanların bilgi paylaş1mında bulunmasına da etki eden birçok bireysel ve örgütsel faktör bulunmaktadır ve bu faktörlerin belirlenmesi bilgi paylaşımını artırabilmek için önem teşkil eder. Bu çalışma kapsamında ele alınan ve bireyin çevresiyle arasındaki anahtar bağlantı olarak tanımlanan (Kozlowski ve Doherty, 1989, s. 546) örgüt ikliminin her iki davranışla da ilişkili olduğu düşünülmektedir. Uygun bir örgüt iklimi hem bilgi paylaşımına yardım edecek hem de çalışanların yenilikçi iş davranışı göstermesine ortam sağlayacaktir.

Ama tabi bütün örgütsel süreçlerde olduğu gibi gerçekte ne olduğundan çok nasıl algılandığı önemli olan iklim, çalışma ortamının nesnel özellikleri ile bireylerin cevapları arasındaki ilişkiye aracılık etmektedir. Yani bireyler çalışma ortamındaki değişkenlere doğrudan tepki göstermezler, algilar ve yorumlarlar (Carr, Schmidt, Ford, ve DeShon, 2003, s. 605). Bu yüzden çoğu zaman örgüt ikliminden kasıt örgüt iklimi algısıdır.

Bu çalışmada örgüt iklimi algısının hem bilgi paylaşımı ile hem de yenilikçi iş davranışı ile olan ilişkisi ortaya konulmaya çalışılmıştır. Bu ilişki 
ağında incelen başka bir ilişki de bilgi paylaşımı ile yenilikçi iş davranışı arasindadir.

\section{Bilgi Paylaşımı}

Bilgi paylaşımını temelde bilgiyi kuruluş içindeki diğer kişilere sunma/yayma eylemi olarak tanımlamak mümkündür (Ryu, Ho ve Han, 2003, s. 113). Bilgi paylaşımı tek seferlik bir faaliyet değil, bireylerin karş1lıklı olarak sahip oldukları bilgilerini (örtük ve açı) paylaştıkları ve birlikte yeni bilgiler oluşturdukları bir süreçtir (Hooff ve Ridder, 2004, s. 118). Örgütler, bireysel bilgiyi örgütsel bilgi haline getirecek bu faaliyeti artırmaya çalışmaktadırlar. Bu amaçla ilgili literatürde çalışanların bilgi paylaşımında bulunmalarını engelleyen birçok faktör ortaya konulmuştur. Bu faktörlerden bir kısmı bireysel özelliklerden kaynaklanmakta iken diğer bir kısmı ise örgütsel özelliklerden kaynaklanmaktadır. Bilgi paylaşımını engelleyen bireysel faktörler olarak bilgiyi güç olarak kullanmak için kendine saklama, fikirlerin çalınmasından korkma, zayıf iletişim, yalnız çalışma kültürü, sahip olunan bilginin çok özelleşmiş olması, diğer meslektaşlarına duyulan güvensizlik, bilgi paylaşımına zaman ayıramama, sahip olunan bilginin değerini bilememe (Hussein ve Wahba, 2003, s. 259; Riege, 2005, s. 23; Farooq, 2018, s. 242) gibi faktörler ele alınmıştır. Örgütsel faktörler olarak ise açık iletişimi sağlayan liderlik eksikliği, bilgi paylaşımına yönelik ödül ve teşviklerin yetersiz olması, kurum kültürünün bilgi paylaşımını engelleyici bir rol oynaması, fiziksel iş çevresinin bilgi paylaşımı yapmayı zorlaştırması, çalışanlar arası rekabetin fazla olması (Riege, 2005, s. 26; Farooq, 2018, s. 242) gibi faktörlere yer verilmiştir. Bireylere ve örgütlere has bu faktörlerin ortadan kaldırılması ile bilgi paylaşımı davranışının artacağı beklenilebilir. Bilgi paylaşımı davranışı arttıkça da çalışanların yenilikçi iş davranışı göstermeleri kolaylaşacaktır.

\section{Yenilikçi İş Davranışı}

Her örgüt için önemli hale gelmiş olan yenilikçi olabilmek yetisinin kazanılabilmesi için çalışanların yenilikçi olmaları için teşvik edilmesi gerekir (Agarwal, 2014a, s. 43). Yenilikçi iş davranışı gösteren çalışanlardan oluşmuş bir örgüt yenilikçi olabilmenin önünü açmış olmaktadır. Yenilikçi iş 
davranışı (YID), bir inovasyonun geliştirilmesi için gerekli bir dizi bağımsız yenilik görevini yerine getirmek için çalışanların bireysel ya da sosyal etkileşimle iş bağlamında yürüttükleri tüm fiziksel ve bilişsel çalışma faaliyetlerinin toplamı şeklinde tanımlanmaktadır (Messmann ve Mulder, 2012, s. 45). Yenilikçi iş davranışları, örgütlerin hayatta kalması, sürdürülebilirliği ve büyümesi için hayati öneme sahiptir. Ancak, YİD göstermek çalışanlar için ekstra bir rol davranışıdır. Bu ise YİD gösteren çalışanın bu davranışı nedeniyle anında ödüllendirilmediği veya söz konusu davranışı göstermediği takdirde bir yaptırıma maruz kalmadığı anlamına gelir.

Scott ve Bruce'a (1994) ve onların çalışmasını esas alan Janssen'a (2000) göre işyerinde YİD, fikir üretimi, fikir tanıtımı ve fikir gerçekleştirme olmak üzere üç farklı görevden oluşan karmaşık bir davranıştır. Bireysel yenilik, herhangi bir alanda yeni ve yararlı fikirlerin üretilmesiyle başlar. Bu yeni fikirlerin ortaya çıkışlarında genellikle işle ilgili algılanan sorunlar, uyumsuzluklar ve yeni ortaya çıkan eğilimler etkilidir. Bir sonraki aşama olan fikir tanıtımında yeni bir fikir ortaya çıaran çalışan, bu fikri destekleyecek bir çevre oluşturmayı amaçlar. Son aşamada ise fikrin uygulanabilecek bir prototipi veya modeli oluşturulur. Basit inovasyonlar çoğunlukla ilgili çalışanlar tarafından tamamlanırken, daha karmaşık inovasyonların başarılması genellikle çeşitli özel bilgi, yeterlilik ve iş rollerine dayanan takım çalışmasını gerektirir (Janssen, 2000, s. 288; Scott ve Bruce, 1994, s. 581-582; Yuan ve Woodman, 2010, s. 324).

Çalışanların yenilikçiliği iş başarısı ve örgütlerin uzun vadede ayakta kalması için kritik öneme sahip olduğundan, örgütler bu davranışları teşvik edebilecek faktörleri incelemeye ilgi duymaktadırlar (Agarwal, 2014b, s. 104). YİD üzerinde olumlu etkisi olan faktörler incelendiğinde Ramamoorthy vd. (2005) çalışmalarında çalışanlara işlerini yapma şekilleri konusunda özerklik sağlamanın YİD üzerinde en güçlü etkiye sahip olduğunu ifade etmişlerdir. Aynı zamanda çalışanların iş yapış şekilleri üzerinde daha az kontrol, işlerini yaparlar iken yeni yöntemler geliştirmelerini sağlayacak bir çevre ve fikirlerini uygulamalarına gösterilen desteğin çalışanların YİD göstermelerine etki edeceğini tespit etmişlerdir. Araştırmacılara göre çalışanların işleri üzerindeki kontrolleri arttıkça iş ile ilgili deneyimlerinin zenginleşmesi sağlanacak ve dolayısıyla yenilik yapmak için daha motive olacaklardır. Bu yüzden iş tasarımları yaparken bunlara 
dikkat etmek önemlidir (Ramamoorthy vd., 2005, s. 148). Çalışanların yenilikçi davranışları göstermesini engelleyen zaman kısıtı, risk almakta isteksizlik, eleştirilerden korkma, uzmanlık gücünü kaybetme endişesi ve iş yükü artışından çekinme gibi çeşitli faktörler vardır (Sanders ve Lin, 2016, s. 35).

YID göstermenin sadece örgüte değil çalışanlara da yararı vardır. Ayrıca, çalışanlar kendi mesleki gelişimleri açısından yenilik sürecine katılımlarından yararlanabilirler. Bir yenilik ortaya çıkarma faaliyetine dâhil olmak, çalışanlara profesyonel olarak gelişim fırsatları sağlayan yeni deneyimlere yol açabilir (Messmann ve Mulder, 2017, s. 142).

Genel olarak olumlu bir özellik olarak düşünülen YİD'nın negatif etkilerini araştıran çalışmalar da literatürde yer almaktadır. Shih ve Susanto (2011) YİD'nın çalışma arkadaşlarıyla çatışma ve işten ayrılma niyeti üzerinde pozitif bir etkisi olduğunu tespit etmişlerdir (Shih ve Susanto, 2011, s. 122).

Yenilikçi davranışa ilişkin daha önce yapılan araştırmalar özellikle kişilik ve motivasyon gibi bireysel özellikler ile ilgiliyken, son çalışmalarda örgüt kültürü ve yöneticilerle ilişkiler gibi örgüt ortamı değişkenlerinin daha önemli olduğu düşünülmektedir (Park, Song, Yoon, ve Kim, 2014, s. 78). Bu bağlamda çalışma kapsamında ele alınan örgüt iklimi örgütün ortamını en iyi yansıtan faktörlerden biridir.

\section{Örgüt İklimi Algısı}

İklim, organizasyondaki yaşamı karakterize eden tutumlar, duygular ve davranışlar topluluğu olarak örgüte has bir özellik olarak kabul edilir ve örgütün üyelerinin algı ve anlayışlarından bağımsız olarak vardır (Ekvall, 1996, s. 105). Örgütsel iklim bir metafordur. Gerçek (meteorolojik) iklim gibi ölçülebilir özelliklere de sahiptir, fakat örgüt iklimi daha çok bireylerin algılarıyla ilgilidir. Bu açıdan örgütün iklimi, bu bireysel algıların kolektif bir ürünü olarak tanımlanabilir (Gray, 2007, s. 9). Örgüt iklimi esasinda örgüt çevresindeki ölçülebilir nesnel özellikler ile kişinin kendine has tercihleri arasındaki uyum tarafından yönlendirilen kişisel bir deneyimdir. Bu yüzden her çalışanın örgüt iklimi algısı farklı olacaktır (Gray, 2007, s. 5). 
Örgüt iklimin, insan davranışlarını ve örgütlerin işleyişini açıklamanın önemi hakkında genel bir fikir birliği bulunmasına rağmen, diğer ilgili kavramlarla örgütsel iklimin arasındaki farklılıklara dair çeşitli görüşler vardır (Al-Shammari, 1992, s. 30). Şüphesiz örgüt iklimi ile farklılığı en çok ortaya koyulmaya çalışılan kavram örgüt kültürüdür. Örgüt iklimi ve örgüt kültürü birbirine bağlı kavramlardır. Çalışanların değerleri ve inançları ki bunlar kültürün bir parçasıdır, örgütsel politikalar, uygulamalar ve prosedürler hakkındaki yorumlarını yani iklimi etkilemektedir (Schneider, Brief, ve Guzzo, 1996, s. 9).

Örgüt iklimi ve örgüt kültürü arasındaki farklara bakıldığında iki kavram arasında önemli farklılıklar olduğunu söylemek mümkündür. İklim bir durumu ve bu durumun örgüt üyelerinin düşünceleri, hisleri ve davranışlarıyla bağlantısını ifade eder. Bu nedenle geçici, öznel ve çoğu zaman güç ve nüfuz sahibi insanlar tarafından doğrudan manipülasyona tabidir. Kültür ise zaman içinde oluşur ve karmaşık olduğu için manipülasyonlara daha dirençlidir (Denison, 1996, s. 644). Kültür öğrenilebilen bir kavram iken iklimle ilgili herhangi bir öğrenme sürecinden bahsedilemez (Al-Shammari, 1992, s. 31).

\section{Kavramlar Arasındaki İlişkiler ve Hipotezlerin Geliştirilmesi}

İklim, bireylerin davranışları ve davranışlarının potansiyel sonuçlarına dair örgütün beklentileri konusunda aldıkları sinyalleri temsil eder (Scott ve Bruce, 1994, s. 582). Örgüt iklimi ile çalışanın yenilik yapmaya hazır olması arasında pozitif bir ilişki vardır (Suliman, 2001, s. 55). Yeni ürün geliştirmede iklimin ve kültürün önemli rolü olduğu görülmektedir (Cooper, Edgett, ve Kleinschmidt, 2004, s. 31). İklim problem çözme, karar verme, iletişim, koordinasyon, kontrol ve öğrenmenin psikolojik süreçleri, motivasyon ve bağll1ık yaratma gibi örgütsel süreçleri etkiler (Ekvall, 1996, s. 106). Yenilikçi iş davranışı da bu örgütsel süreçlerden biri olup örgüt ikliminden etkilenmektedir.

$\mathrm{H}_{1}$ : Algılanan örgüt ikliminin yenilikçi iş davranışı üzerinde anlamlı etkisi vardır.

Örgütsel iklim, çalışanlara hangi davranışın uygun ve arzu edilir olduğunu ileterek rehberlik eder. Çok sayıda çalışma, organizasyonel iklimin rolünü, bilgi paylaşımı davranışının kritik bir unsuru olarak kabul etmiş 
ve bilgi paylaşımına uygun bir organizasyonel iklim yaratma ihtiyacını vurgulamıştır (Anwar ve Prasad, 2013, s. 578). Örgüt iklimi çalışanların sübjektif normları üzerinden bilgi paylaşımını etkiler (Tohidinia ve Mosakhani, 2010, s. 621; Bock, Zmud, Kim, ve Lee, 2005, s. 99).

$\mathrm{H}_{2}$ : Algılanan örgüt ikliminin bilgi paylaşımı üzerinde anlamlı etkisi vardır.

Kuşkusuz ki, birinin bilgiyi aktarma ve kullanma yeteneği, hızlı problem çözme kapasitesi ve değişikliklere daha hızlı tepki verme gibi bireysel inovasyon seviyesini yükseltebilir. Literatürde bilgi paylaşımının yenilikçi iş davranışına etki ettiğini gösteren birçok çalışma (Phung, Hawryszkiewycz, Chandran ve Ha, 2017, s. 8; Akhavan, Hosseini, Abbasi, ve Manteghi, 2015, s. 576; Radaelli, Lettieri, Mura ve Spiller, 2014, s. 407; Mura, Lettieri, Radaelli ve Spiller, 2013, s. 535) yer almaktadır.

- H3: Bilgi paylaşımının yenilikçi iş davranışı üzerinde anlamlı bir etkisi vardır.

- $\mathrm{H}_{1}, \mathrm{H}_{2}$ ve $\mathrm{H}_{3}$ hipotezlerine temel sağlayan literatür neticesinde oluşturulan son hipotez:

- H4: Algılanan örgüt ikliminin yenilikçi iş davranışa etkisinde bilgi paylaşımının aracılık rolü vardır.

Algılanan örgüt ikliminin yenilikçi iş davranışa etkisinde bilgi paylaşımının aracılık rolünü ölçmek için oluşturulan model Şekil 1'deki gibidir.

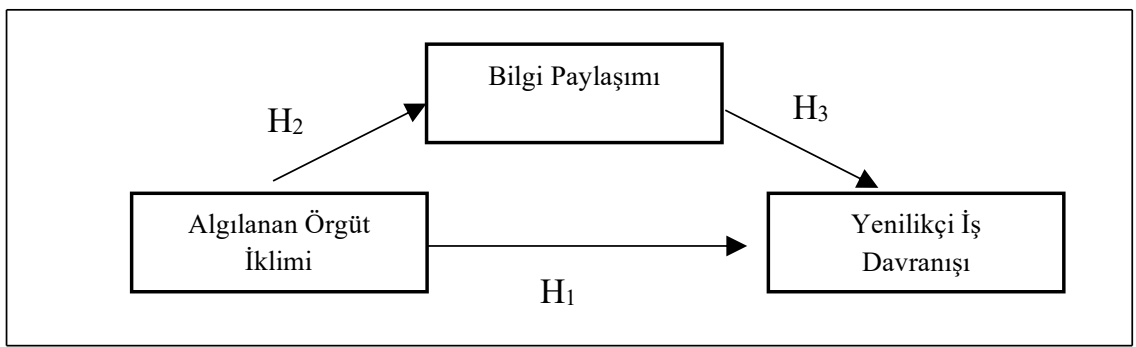

Şekil 1. Araştırmanın Modeli

\section{Yöntem}

\section{Evren ve Örneklem}

Türkiye' de kalkınma ajansları bulundukları bölgede sürdürülebilir bölgesel kalkınmayı hızlandırmak ve bölge içi gelişmişlik farklarını azaltmak 
amacıyla stratejiler geliştirmek, destekler vermek, işbirliği ve koordinasyon sağlamak ve yerel potansiyelleri etkin ve verimli bir şekilde harekete geçirmeyi ana amaç edinmişlerdir (Akbulut, 2018, s. 61).

Kalkınma ajansları bölgesel yenilikçiliğin temel stratejik hedef olarak alındığı bölgesel gelişme politikalarının inşasında yenilik sürecini ortaya çıkaran tüm aktörlerin birbiriyle olan etkileşimini hızlandıracak bir katalizör olarak görülmektedir (Tuncel ve Bakir, 2010, s. 34). Ajansların bu misyonu gerçekleştirebilmeleri için yenilikçi iş davranışına sahip çalışanların olması çok önemlidir.

Algılanan örgütsel iklimin ve bilgi paylaşımının çalışanların yenilikçi iş davranışına etkisinin araştırıldığı bu çalışmada, Türkiye'deki Kalkınma Ajanslarında çalışanlar araştırma evrenini oluşturmaktadır. Çalışmaya katılımı artırmak ve katılımcılara kolaylık ve zaman tasarrufu sağlamak maksadıyla online olarak hazırlanan anketler çalışanlara 2 ay süresince birkaç kez gönderilmiş ve 218 adet anket elde edilmiştir. Bu anketlerden özensiz doldurulanlar çıkartıldıktan sonra 196'sı değerlendirmeye alınmiştır.

\section{Ölçüm Araçları}

Ölçüm aracı olarak soru formu kullanılmıştır. Bilgi Paylaşımı Davranışı Ölçeği, Chennamaneni vd. (2012) tarafından geliştirilmiş ve Töre (2017) tarafından Türkçeye çevrilmiştir. Yenilikçi İş Davranışı Ölçeği Janssen (2000) tarafından geliştirilmiş ve yine Töre (2017) tarafından Türkçeye çevrilmiştir. Örgüt İklimi Ölçeği Stringer (2001) tarafından geliştirilmiş olup Mumcu (2018) tarafından Türkçeye çevrilmiştir.

\section{Araştırma Bulguları}

Katılımcılara dair tanımlayıcı veriler tablo 1'de verilmiştir. Tablo incelendiğinde katılımcıların çoğunluğunu erkek (\%77), 31-40 yaş arası (\%76), lisans mezunu $(\% 68,4)$ ve 6-10 yıl aralığında $(\% 74,5)$ kurumda çalışanların oluşturduğu görülmektedir. 
Tablo 1. Katılımcıların demografik özellikleri

\begin{tabular}{llll}
\hline Değişken & Değişken Değeri & Frekans & Yüzde(\%) \\
\hline \multirow{4}{*}{ Cinsiyet } & Kadın & 45 & 23,0 \\
& Erkek & 151 & 77,0 \\
\hline \multirow{2}{*}{ Yaş } & 21-30 yaş arası & 18 & 9,2 \\
& 31-40 yaş arası & 149 & 76,0 \\
& 41-50 yaş arası & 27 & 13,8 \\
Ĕ̆itim & 50 yaş üzeri & 2 & 1,0 \\
Durumu & Ön Lisans & 9 & 4,6 \\
\hline \multirow{3}{*}{ Kurumda } & Lisans & 134 & 68,4 \\
Çalışma Süresi & Lisansüstü & 53 & 27,0 \\
& 1 yıl ve daha az & 4 & 2,0 \\
& 2-5 yıl & 33 & 16,8 \\
\hline
\end{tabular}

\section{Faktör Analizi Sonuçlarn}

Araştırmada kullanılan tüm ölçekler için açımlayıcı faktör analizi ve doğrulayıcı faktör analizi yapılmıştır. Analizler için SPSS istatistik paket programı ve Amos paket programı kullanılmıştır.

Bilgi Paylaşımı Ölçeği'nin Açımlayıcı ve Doğrulayıcı Faktör Analizi Sonuçlart

Chennamaneni vd. (2012) tarafından geliştirilen ve 4 ifadeden oluşuna bilgi paylaşımı ölçeğinde yapılan açımlayıcı faktör analizi sonucunda Kaiser-Meyer-Olkin Ölçüm Yeterliliği .839, Bartlett Test Chi-Square 511,668 bulunmuştur (Sig. .000). Cronbach's Alpha değeri 907 olarak bulunmuştur. Toplam 4 ifadeden oluşan ölçek tek faktörde toplanmıştır. Ölçeğin toplam açıklama gücü \%71,223 olarak gerçekleşmiştir.

Tablo 2. Bilgi paylaşımı ölçeği açımlayıcı faktör analizi sonuçları

\begin{tabular}{ll}
\hline Bilgi Paylaşımı & Faktör Yükü \\
\hline İşle ilgili teorik bilgilerimi, çalışma arkadaşlarım ile paylaşırım. & 0,878 \\
\hline $\begin{array}{l}\text { Eğitim ve öğretimle edindiğim uzmanlığımı, çalışma arkadaşlarımla } \\
\text { paylaşırım. }\end{array}$ & 0,870 \\
\hline $\begin{array}{l}\text { Yaptığım işin sırrını ve nasıl yapıldığını, çalışma arkadaşlarımla } \\
\text { paylaşırım. }\end{array}$ & 0,837 \\
\hline İş deneyimlerimi, çalışma arkadaşlarımla paylaşırım. & 0,788 \\
\hline
\end{tabular}


Tablo 3. Bilgi paylaşımı (BP) ölçeği DFA sonuçlarında ulaşılan uyum indeksleri dĕ̆erleri

\begin{tabular}{llll}
\hline İndeks & $\begin{array}{l}\text { BP Ölçeği Uyum } \\
\text { İndeksleri }\end{array}$ & Normal Değer & $\begin{array}{l}\text { Kabul Edilebilir } \\
\text { Değer }\end{array}$ \\
\hline CMIN/DF & 2.881 & $\leq 3$ & $\leq 5$ \\
GFI & 0.98 & $\geq 0.95$ & $\geq 0.90$ \\
CFI & 0.99 & $\geq 0.95$ & $\geq 0.90$ \\
NFI & 0.99 & $\geq 0.95$ & $\geq 0.90$ \\
RFI & 0.97 & $\geq 0.95$ & $\geq 0.90$ \\
TLI & 0.98 & $\geq 0.95$ & $\geq 0.90$ \\
RMSEA & 0.09 & $\leq 0.05$ & $\leq 0.10$ \\
\hline
\end{tabular}

Tablo incelendiğinde bilgi paylaşımı ölçeği DFA sonucunda ulaşılan uyum indekslerinin kabul edilebilir uyum derecesinde olduğu görülmektedir. Bu model ile veri uyumunun olduğu anlamına gelmektedir.

\section{Örgüt İklimi Ölçeği'nin Açımlayıcı ve Doğrulayıcı Faktör Analizi Sonuçları}

Araştırmada Stringer (2001) tarafından geliştirilen örgüt iklimi ölçeği kullanılmıştır. Toplam 24 ifadeden oluşan ölçekte 6 boyut bulunmaktadır. Bu boyutlar örgütsel yapı, sorumluluk, fark edilme, destek, standartlar ve bağlllık olarak belirlenmiştir. Ölçeğe ait her bir boyut 4 ifade ile ölçülmektedir. Yapılan faktör analizi sonucunda bazı ifadelerin faktör yüklerinin yeterli düzeye ulaşmadığı tespit edilmiştir. Standartlar boyutundaki 4 ifade, sorumluluk boyutundaki 4 ifade ve örgüt yapısı boyutundaki 1 ifade bu sebepten analizden çıkarılmıştır. Geriye kalan 15 ifadeye ait açımlayıcı faktör analizi tablo 4 'deki gibidir.

Yapılan açımlayıcı faktör analizi sonucunda Kaiser-Meyer-Olkin Ölçüm Yeterliliği .923, Bartlett Test Chi-Square 3266,0,97 bulunmuştur (Sig. .000). Cronbach's Alpha değeri 956 olarak bulunmuştur. Toplam 15 ifadeden oluşan ölçek dört faktörde toplanmıştır. Ölçeğin toplam açıklama gücü \%82,755 olarak gerçekleşmiştir. 
Tablo 4. Örgüt iklimi (Öİ) ölçeği açımlayıcı faktör analizi sonuçları

\begin{tabular}{|c|c|}
\hline Örgüt Yapısı & Faktör Yükü \\
\hline $\begin{array}{l}\text { Bu kurumda işler açıkça tanımlanmış ve mantıklı bir biçimde yapılandı- } \\
\text { rılmıştır. }\end{array}$ & 0,947 \\
\hline $\begin{array}{l}\text { Görev aldığım bazı işlerde üstümün tam olarak kim olduğuna karar vere- } \\
\text { mediğim zamanlar olur. }\end{array}$ & 0,912 \\
\hline $\begin{array}{l}\text { Çalıştı̆̆ım kurumda kimin resmi karar verme yetkisine sahip olduğu bazı } \\
\text { durumlarda belirsizdir. }\end{array}$ & 0,897 \\
\hline Fark Edilme & Faktör Yükü \\
\hline $\begin{array}{l}\text { Bu kurumda çalışanlar iş performanslarının mükemmelliği oranında } \\
\text { ödüllendirilir. }\end{array}$ & 0,979 \\
\hline $\begin{array}{l}\text { Çalıştığım kurumda en iyilerin üst kademelere doğru yükselmesine ola- } \\
\text { nak sağlayan bir terfi sistemi vardır. }\end{array}$ & 0,872 \\
\hline $\begin{array}{l}\text { Çalıştığım kurumda yapılan işler yeterince fark edilmez ve ödüllendiril- } \\
\text { mez. }\end{array}$ & 0,867 \\
\hline $\begin{array}{l}\text { Bu kurumda ödül ve teşvikler genellikle ceza ve tehditlerden daha fazla } \\
\text { kullanılmaktadır. }\end{array}$ & 0,734 \\
\hline Destek & Faktör Yükü \\
\hline $\begin{array}{l}\text { Çalıştığım kurumda hata yapanlar üstlerinden çok fazla anlayış görmez- } \\
\text { ler. }\end{array}$ & 0,914 \\
\hline $\begin{array}{l}\text { Zor bir görev üstlendiğim zaman genellikle, üstüm ve çalışma arkadaşla- } \\
\text { rımdan yardım alabileceğimi bilirim. }\end{array}$ & 0,887 \\
\hline İyi çalışan bir takımın üyesi olduğumu düşünüyorum. & 0,882 \\
\hline Bu kurumdaki çalışanlar gerçekten birbirine yeterince güvenmez. & 0,812 \\
\hline Bağlılık & Faktör Yükü \\
\hline Çalışanlar bu kuruma ait olmaktan dolayı gurur duyar. & 0,935 \\
\hline Bu kuruma ne olacağı aslında çok da umurumda değildir. & 0,881 \\
\hline Çalıştığım kurumun amaçlarını genellikle ciddi anlamda benimserim. & 0,876 \\
\hline $\begin{array}{l}\text { Görebildiğim kadarıyla çalışanların bu kuruma fazla kişisel bağl1lıkları } \\
\text { yoktur. }\end{array}$ & 0,799 \\
\hline
\end{tabular}

Tablo 5. Örgüt iklimi ölçeği (ÖI) DFA sonuçlarında ulaşılan uyum indeksleri değerleri

\begin{tabular}{llll}
\hline İndeks & $\begin{array}{l}\text { BP Ölçeği Uyum } \\
\text { İndeksleri }\end{array}$ & $\begin{array}{l}\text { Normal } \\
\text { Değer }\end{array}$ & $\begin{array}{l}\text { Kabul Edilebilir } \\
\text { Değer }\end{array}$ \\
\hline CMIN/DF & 1,704 & $\leq 3$ & $\leq 5$ \\
GFI & 0,91 & $\geq 0.95$ & $\geq 0.90$ \\
CFI & 0,98 & $\geq 0.95$ & $\geq 0.90$ \\
NFI & 0,96 & $\geq 0.95$ & $\geq 0.90$ \\
RFI & 0,95 & $\geq 0.95$ & $\geq 0.90$ \\
TLI & 0,98 & $\geq 0.95$ & $\geq 0.90$ \\
RMSEA & 0,06 & $\leq 0.05$ & $\leq 0.10$ \\
\hline
\end{tabular}




\section{Yenilikçi İş Davranışı Ölçeği'nin Açımlayıcı ve Doğrulayıcı Faktör Analizi Sonuçlarn}

Yenilikçi İş Davranışı Ölçeği, Janssen (2000) tarafından geliştirilmiştir. Ölçek 9 ifade ve fikir üretme, fikir destekleme ve fikir uygulama olmak üzere 3 boyuttan oluşmaktadır.

Yapılan açımlayıcı faktör analizi sonucunda Kaiser-Meyer-Olkin Ölçüm Yeterliliği .942, Bartlett Test Chi-Square 1516,361 bulunmuştur (Sig. .000). Cronbach's Alpha değeri .949 olarak bulunmuştur. Toplam 9 ifadeden oluşan ölçekte ifade sayısı korunmuş ve tek faktörde toplanmıştır. Ölçeğin toplam açıklama gücü \%67,445 olarak gerçekleşmiştir.

Tablo 6. Yenilikçi iş davranışı ölçeği (YİD) açımlayıcı faktör analizi sonuçları

\begin{tabular}{ll}
\hline Yenilikçi İş Davranışı & Faktör Yükü \\
\hline Zor durumlar için yeni fikirler üretirim. & 0,861 \\
Yeni çalışma metotlarını, tekniklerini ve araçlarını araştırırım. & 0,861 \\
Çalışma ortamımda, düzenli olarak yenilikçi fikirler öneririm. & 0,849 \\
Yenilikçi fikirlerin faydasını değerlendiririm. & 0,832 \\
Yenilikçi fikirleri, kullanışlı uygulamalara dönüştürürüm. & 0,819 \\
Çalışma arkadaşlarımın yenilikçi fikirler için heyecanlanmasını & 0,810 \\
önemserim. & \\
Yenilikçi fikirleri desteklerim. & 0,795 \\
Yenilikçi fikirlerin edinilmesini takdir ederim. & 0,781 \\
Problemler için orijinal çözümler üretirim. & 0,779 \\
\hline
\end{tabular}

Tablo 7. Yenilikçi iş davranışı (YiD) ölçeği DFA sonuçlarında ulaşılan uyum indeksleri değerleri

\begin{tabular}{llll}
\hline İndeks & $\begin{array}{l}\text { BP Ölçeği Uyum } \\
\text { İndeksleri }\end{array}$ & $\begin{array}{l}\text { Normal } \\
\text { Değer }\end{array}$ & Kabul Edilebilir Değer \\
\hline CMIN/DF & 1,054 & $\leq 3$ & $\leq 5$ \\
GFI & 0,97 & $\geq 0.95$ & $\geq 0.90$ \\
CFI & 0,99 & $\geq 0.95$ & $\geq 0.90$ \\
NFI & 0,98 & $\geq 0.95$ & $\geq 0.90$ \\
RFI & 0,97 & $\geq 0.95$ & $\geq 0.90$ \\
TLI & 0,99 & $\geq 0.95$ & $\geq 0.90$ \\
RMSEA & 0,02 & $\leq 0.05$ & $\leq 0.10$ \\
\hline
\end{tabular}

Analiz sonucunda elde edilen ortalamalar, standart sapmalar ve korelasyon değerleri Tablo 8'de yer almaktadır. 
Tablo 8. Verilere ilişkin ortalama, standart sapma ve korelasyon değerleri

\begin{tabular}{llllll}
\hline & Ort. & S.S. & Ö̇ & BP & YİD \\
\hline Öİ & 3,640 & 0,748 & 1 & & \\
BP & 3,769 & 0,680 & $0,598^{* *}$ & 1 & \\
YİD & 3,996 & 0,717 & $0,858^{* *}$ & $0,635^{* *}$ & 1 \\
\hline
\end{tabular}

Analizde çoklu doğrusal bağlantı sorunu olup olmadığını belirlemek maksadıyla doğrudaşlığa (collinearity) bakılmıştır. Elde edilen tolerans ve VIF değerleri algılanan örgüt iklimi ile bilgi paylaşımı arasında çoklu bağlantı olmadığını göstermiştir (Tolerans: ,642 > .2, VIF: 1,557< 10).

\section{Yapısal Eşitlik Modellemesi Amos ile Aracılık Etkisi Analizi}

Örgüt iklimi algısının yenilikçi iş davranışı üzerinde etkisinde bilgi paylaşımının aracılık etkisini ölçmek için SPSS Amos paket programı ile Şekil 1'deki modeli test etmeden önce $\mathrm{H}_{1}, \mathrm{H}_{2}, \mathrm{H}_{3}$ hipotezlerini test etmek gerekir. $\mathrm{H}_{1}$ hipotezini test etmek için kurulan model Şekil 2'deki gibidir.

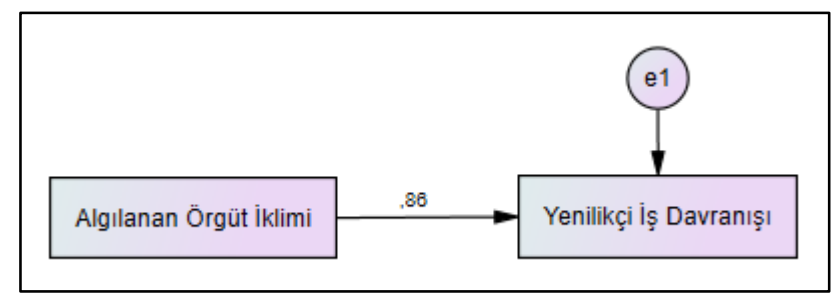

Şekil 2. H1 hipotezine ait test edilen model

\begin{tabular}{|c|c|c|c|c|}
\hline Regression Weights & Estimate & S.E. & C.R. & $\mathrm{P}$ \\
\hline yenisd <--- orgikl & 822 & 035 & 23,285 & $* * *$ \\
\hline Standardized Regression Weights & Estimate & & & \\
\hline yenisd <--- orgikl & 858 & & & \\
\hline
\end{tabular}

Analiz sonuçlarına göre algılanan örgüt ikliminin yenilikçi iş davranışı üzerinde anlamlı etkisi vardır. $\mathrm{H}_{1}$ hipotezi kabul edilmiştir. 


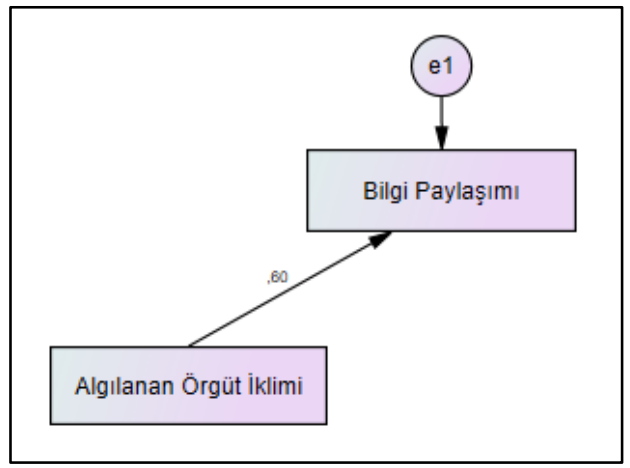

Şekil 3. $\mathrm{H}_{2}$ hipotezine ait test edilen model

\begin{tabular}{|c|c|c|c|c|}
\hline Regression Weights & Estimate & S.E. & C.R. & $\mathrm{P}$ \\
\hline bilpay <--- orgikl &, 544 & ,052 & 10,425 & $* * *$ \\
\hline Standardized Regression Weights & Estimate & & & \\
\hline bilpay <--- orgikl &, 598 & & & \\
\hline
\end{tabular}

Analiz sonuçlarına göre algılanan örgüt ikliminin bilgi paylaşımı üzerinde anlamlı etkisi vardır. $\mathrm{H}_{2}$ hipotezi kabul edilmiştir.

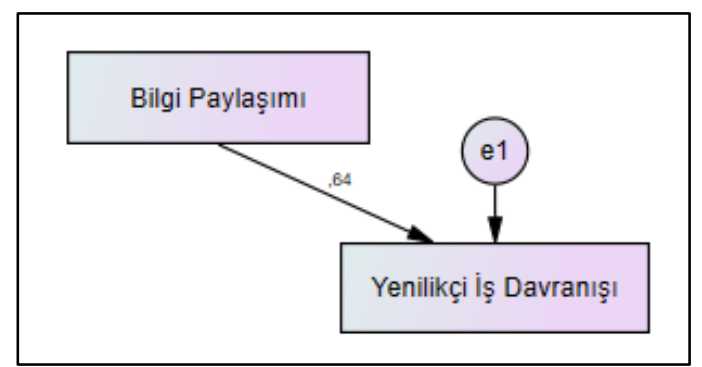

Şekil 4. $H_{3}$ hipotezine ait test edilen model

\begin{tabular}{|c|c|c|c|c|}
\hline Regression Weights & Estimate & S.E. & C.R. & $\mathrm{P}$ \\
\hline yenisd <--- bilpay & ,670 & ,058 & 11,489 & *** \\
\hline Standardized Regression Weights & Estimate & & & \\
\hline yenisd <--- bilpay & 635 & & & \\
\hline
\end{tabular}

Analiz sonuçlarına göre bilgi paylaşımının yenilikçi iş davranışı üzerinde anlamlı bir etkisi vardır. $\mathrm{H}_{3}$ hipotezi kabul edilmiştir. 


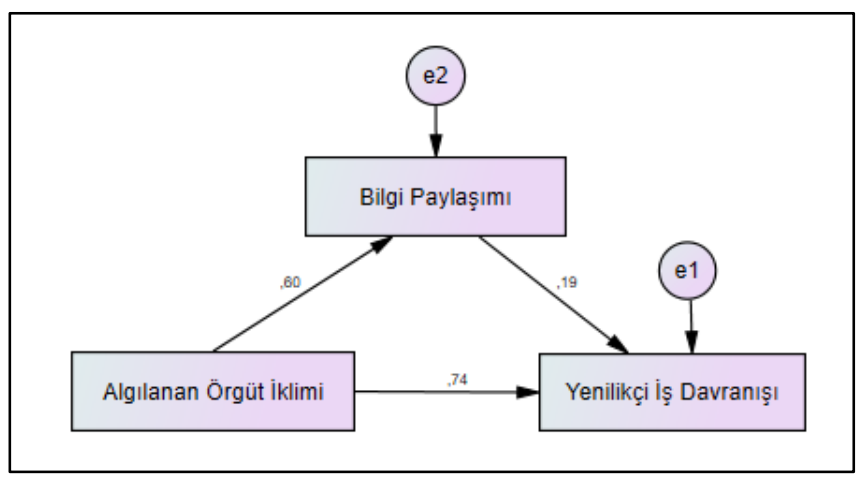

Şekil 5. H4 hipotezine ait test edilen model

\begin{tabular}{|c|c|c|c|c|}
\hline Regression Weights & Estimate & S.E. & C.R. & $\mathrm{P}$ \\
\hline bilpay <--- orgikl &, 544 & 052 & 10,425 & *** \\
\hline yenisd <--- bilpay & ,201 & 046 & 4,340 & $* * *$ \\
\hline yenisd <--- orgikl & ,713 & 042 & 16,943 & *** \\
\hline Standardized Regression Weights & Estimate & & & \\
\hline bilpay $<---$ orgikl & ,598 & & & \\
\hline yenisd <--- bilpay & 190 & & & \\
\hline yenisd <--- orgikl & ,744 & & & \\
\hline
\end{tabular}

Aracılık etkisi analizinde, bir bağımsız değişkenin bir bağımlı değişkene etkisinde başka bir bağımsız değişken modele girdikten sonra bu ilişkinin düşmesi veya yok olması beklenir. Etki yok oluyorsa tam aracılık, bir düşme söz konusu ise kısmi aracılıktan söz edilebilir.

Algılanan örgüt ikliminin yenilikçi iş davranışına etkisi anlamlı ve regresyon katsayısı 0,858 olarak bulunmuştur. Bilgi paylaşımı değişkeni modele dâhil edildiğinde ise bu etkinin yine anlamlı olduğu fakat regresyon katsayısının 0,744'a düştüğü görülmektedir. Bundan dolayı bilgi paylaşımının yenilikçi iş davranışına etkisinde örgüt ikliminin kısmi aracılık etkisinden söz edebiliriz. Amos yazılımı ile analizde standardize endirekt etkilerin "Lower Bounds" ve "Upper Bounds" değerleri 0,070 ve 0,159 olarak ölçülmüştür. Bu da aracılık etkisinin pozitif ve bu aralıklar içerisinde olduğunu göstermektedir. Oluşturulan aracılık analizinin anlamlılık değeri (Standardized Indirect Effects - Two Tailed Significance) $p=0,008<0,05$ olduğundan aracılık etkisini ölçen model geçerli ve anlamlıdır. $\mathrm{H}_{4}$ hipotezi kabul edilmiştir. 


\section{Sonuç}

Ekonomistlerin toprak, sermaye ve emek gibi sonlu kaynaklarının aksine, bilgi ve entelektüel sermaye, sistematik kullanımları ve uygulamaları ile artan getiri sağlayabilen sonsuz kaynaklardır (Tiwana, 2000, s. 42). Günümüzde sadece işletmelerin değil her örgütün yenilikçi olması gerekmektedir. Yenilikçi örgüt olabilmenin ilk adımı ise bu sonsuz kaynağa sahip olmaktır. Bilginin sonsuzluğu, kendini yenileyebilme gücünden gelmektedir. Bireyler yeni bilgi üretimi için diğer bireylerin bilgisine de ihtiyaç duymaktadırlar. Bu noktada bilgi paylaşımı kavramı ortaya çıkmaktadır. Görünürde bilgi paylaşımı yapılması kendiliğinden gerçekleşen doğal bir örgütsel süreç olarak düşünülebilir. Ancak uygulamada çalışanların bilgi paylaşımı yapmasını engelleyen birçok bireysel ve örgütsel neden vardır. Bunlar aşıldığında çalışanlar bilgi paylaşımında bulunacak bu ise yenilikçi iş davranışı göstermenin kapısını açacaktır. Çalışanların yenilikçi iş davranışı göstermesini isteyen örgütler bilgi paylaşımı yapmalarını motive etmelidirler (Carmeli, Gelbard, ve Reiter-Palmon, 2013, s. 96). Tipk1 bilgi paylaşımında olduğu gibi yenilikçi iş davranışı göstermeye de birçok bireysel ve örgütsel faktör etki etmektedir. Bu noktada örgüt iklimi her iki davranış için de etkiye sahip olan örgüte has bir faktördür. Örneğin güven, iletişim kolaylığ 1 ve bilgi paylaşımının ödüllendirildiği bir iklim, çalışanları bilgi paylaşmaya yönlendirirken (Gupta, 2008, s. 186; Hooff ve Ridder, 2004, s. 117) yaratıcılığı teşvik eden, çalışanlarına özerklik sağlayan ve güçlü bir örgütsel destek algısı sunan bir iklim de çalışanları yenilikçi iş davranışı göstermeye itecektir (Hunter, Bedell, ve Mumford, 2007, s. 69; DiLiello ve Houghton, Maximizing organizational leadership capacity for the future: Toward a model of self-leadership,innovation ve creativity, 2006, s. 319).

Bu çalışma kapsamında ele alınan üç değişkenin birbirleriyle ilişkileri incelenmiştir. Analiz sonucunda algılanan örgüt ikliminin yenilikçi iş davranışı üzerinde, algılanan örgüt ikliminin bilgi paylaşımı üzerinde ve bilgi paylaşımının da yenilikçi iş davranışı üzerinde anlamlı bir etkisi olduğu görülmüştür. Bu sonuçlar esasında literatürle uyumlu olup (Radaelli vd. 2014; Anwar ve Prasad, 2013; Mura vd., 2013; Bock vd., 2005; Suliman, 2001; Ekvall, 1996) beklendiği şekildedir. Ayrıca örgüt ikliminin yenilikçi iş davranışına etkisinde bilgi paylaşımının kısmi aracılık etkisi 
olduğu bulunmuştur. Araştırmacı olmak, yeni teknikleri ve metotları bulmak ve kullanmak, yeni fikirler üretmek için çalışanların kendi aralarında bilgiyi mümkün olduğunca paylaşmaları önemlidir. Ancak bu bilgi paylaşımının ileri düzeylerde olabilmesinin elverişli bir örgüt iklimi sayesinde mümkün olabileceği söylenebilir.

Her çalışmanın olduğu gibi bu çalışmanın da çeşitli kısıtları mevcuttur. Özellikle veri azlığı bu kısıtların başını çekmektedir. Ancak günümüz koşullarında herhangi bir örneklem için de yine bu kısıt var olacaktır. Ayrıca yine veri toplama yöntemi olarak kullanılan anket yönteminin de kendine has kısıtları bu çalışmada da görülmüştür. Yeniliğe ve bilgi üretmeye önem veren başka örgütlerde de benzer çalışmaların yapılmasıyla örgüt ikliminin ve bilgi paylaşımının yenilikçi iş davranışına etkileri daha net ortaya koyulabilecek kavramlar arasındaki ilişkilerin farklı boyutları da görülebilecektir. 


\title{
EXTENDED ABSTRACT
}

\section{An Empirical Study on the Mediating Effect of Knowledge Sharing on the Relationship between Organizational Climate Perception and Innovative Work Behavior}

\author{
Sema Yiğit - Alperen M. Yiğit
}

Ordu University

In today's knowledge-intensive economy, the current knowledge of an organization and its ability to use this knowledge in innovation activities are becoming an increasingly important resource. Innovative employees play important roles at this point. These employees have the motivation and ability to obtain information and build a foundation that brings the organization to innovation. However, the fact that individual knowledge becomes organizational knowledge is very important for innovation activities in the organization. In this context, information sharing helps to facilitate the acquisition of new information by exchanging information and helps individual information to become organizational information and to gain a kind of institutional identity. In this context, it is important to have employees with innovative business behavior in an organization, while sharing this information will be of particular importance. Given the necessity of being innovative at the employee level to realize innovation activities at the organizational level, there is growing interest among researchers on the reasons and conditions which encourage innovative work behavior.

Previous research on innovative work behavior is particularly related to individual characteristics such as personality and motivation, while recent studies suggest that organizational environment variables, such as organizational culture and relations with managers, are more important. The organizational climate, which is considered as the key link between the individual and his / her environment, is thought to be related to both behaviors. An appropriate organizational climate will both help to share information and provide an environment for employees to demonstrate 
innovative work behavior. In this study, the relationship between organizational climate perception both knowledge sharing and innovative work behavior is tried to be revealed. Another relationship examined in this relationship network is between information sharing and innovative business behavior. The model created to analyze these relationships between variables is as follows:

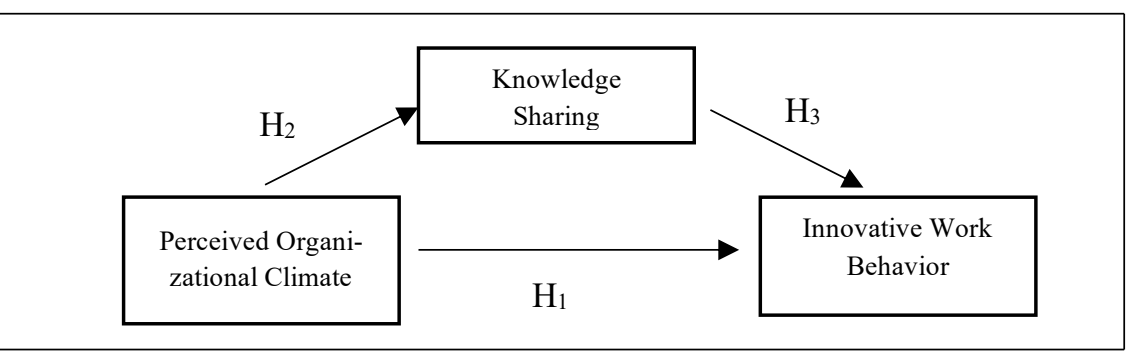

Figure 1. Research Model

The hypotheses generated are as follows:

- H1: The perceived organizational climate has a significant effect on innovative work behavior.

- $\mathrm{H}_{2}$ : Perceived organizational climate has a significant effect on information sharing.

- $\mathrm{H}_{3}$ : Knowledge sharing has a significant effect on innovative business behavior

- The last hypothesis that was formed as a result of the literature which provides the basis of $\mathrm{H}_{1}, \mathrm{H}_{2}$, and $\mathrm{H}_{3}$ hypothesis:

- $\mathrm{H}_{4}$ : Information sharing has a mediating role in the impact of perceived organizational climate on innovative work behavior.

The target population of this study is employees who works in development agencies in Turkey. Development agencies in Turkey are working to accelerate sustainable regional development, to make strategies for reducing the regional development gap, to ensure cooperation and coordination and to mobilize local potentials effectively and efficiently in the region where they operate. In order to increase participation in the study and provide convenience and time savings, online questionnaires were sent to the employees several times over a period of 2 months and 218 
questionnaires were obtained. 196 of these surveys were taken into consideration after sloppy fillings were removed. Questionnaire was used as a measurement tool. Knowledge Sharing Behavior Scale was developed by Chennamaneni et al. (2012) and translated into Turkish by Töre (2017). The Innovative Work Behavior Scale was developed by Janssen (2000) and translated into Turkish by Töre (2017). Organizational Climate Scale was developed by Stringer (2001) and translated into Turkish by Mumcu (2018).

Firstly, validity and reliability analyses were performed. The hypotheses generated by the relevant literature review were tested with the help of SPSS and AMOS programs. As a result of the analysis, it was revealed that perceived organizational climate had a significant effect on innovative work behavior and knowledge sharing. It is also revealed that knowledge sharing had a significant effect on innovative work behavior.

These results are essentially consistent with the literature (Radaelli et al. 2014; Anwar and Prasad, 2013; Mura et al., 2013; Bock et al., 2005; Suliman, 2001; Ekvall, 1996) as expected. In addition, it was found that information sharing has a partial mediation effect on the impact of perceived organizational climate on innovative work behavior. In order to find and use new techniques and methods, to produce new ideas, it is important that employees share information as much as possible. However, it can be said that this information sharing is possible in advanced levels thanks to a favorable organizational climate.

As with every study, this study has several limitations. In particular, the scarcity of data leads to these constraints. However, this constraint will still exist for any sample. In addition, the specific limitations of the questionnaire method used as a data collection method were also observed in this study.

\section{Kaynakça / References}

Agarwal, U. A. (2014a). Linking justice, trust and behaviour. Personnel Review, $43(1), 41-73$.

Agarwal, U. A. (2014b). Examining the impact of social exchange relationships on innovative work behaviour Role of work engagement. Team Performance Management, 20(3/4),102-120. 
Akbulut, M. U. (2018). Küreselleşme süreci ve bölgesel kalkınma ajansları. Osmaniye Korkut Ata Üniversitesi İktisadi ve İdari Bilimler Fakültesi Dergisi, 2(1),54-63.

Akhavan, P., Hosseini, S. M., Abbasi, M., ve Manteghi, M. (2015). Knowledgesharing determinants, behaviors, and innovative work behaviors: An integrated theoretical view and empirical examination. Aslib Journal of Information Management, 67(5),562-591.

Al-Shammari, M. M. (1992). Organizational climate. Leadership \& Organization Development Journal, 13(6),30-32 .

Anwar, S., ve Prasad, K. D. (2013). Factors contributing to teachers' attitude towards knowledge sharing. Driving the economy through innovation and entrepreneurship: Emerging agenda for technology management içinde (s. 573-584). New Delhi: Springer India.

Bock, G.-W., Zmud, R. W., Kim, Y.-G., ve Lee, J.-N. (2005). Behavioral intention formation in knowledge sharing: examining the roles of extrinsic motivators, social-psychological forces, and organizational climate. MIS Quarterly, 29(1),87-111.

Carmeli, A., Gelbard, R., ve Reiter-Palmon, R. (2013). Leadership, creative problem-solving capacity, and creative performance: The importance of knowledge sharing. Human Resource Management, 52(1),95-122.

Carr, J. Z., Schmidt, A. M., Ford, J. K., ve DeShon, R. P. (2003). Climate perceptions matter: A meta-analytic path analysis relating molar climate, cognitive and affective states, and individual level work outcomes. Journal of Applied Psychology, 88(4),605-619.

Chennamaneni, A., Teng, J. T., ve Raja, M. (2012). A unified model of knowledge sharing behaviours: theoretical development and empirical test. Behaviour \& Information Technology, 31(11),1097-1115.

Cooper, R. G., Edgett, S. J., ve Kleinschmidt, E. J. (2004). Benchmarking best NPD practices-1. Research-Technology Management, 47(1),31-43.

Denison, D. R. (1996). What is the difference between organizational culture and organizational climate? A native's point of view on a decade of paradigm wars. The Academy of Management Review, 21(3),619-654.

DiLiello, T. C., ve Houghton, J. D. (2006). Maximizing organizational leadership capacity for the future: Toward a model of self-leadership, innovation and creativity. Journal of Managerial Psychology, 21(4),319-337.

Ekvall, G. (1996). Organizational climate for creativity and innovation. European Journal of Work and Organizational Psychology, 5(1),105-123 . 
Farooq, R. (2018). A conceptual model of knowledge sharing. International Journal of Innovation Science, 10(2), 238-260.

Gray, R. (2007). A climate of success: Creating the right organization climate for high performance. Oxford: Elsevier.

Gupta, K. S. (2008). A comparative analysis of knowledge. Knowledge and process management, 15(3), 186-195.

Hooff, B. V., ve Ridder, J. A. (2004). Knowledge sharing in context: the influence of organizational commitment, communication climate and $\mathrm{CMC}$ use on knowledge sharing. Journal of Knowledge Management, 8(6), 117-130.

Hunter, S. T., Bedell, K. E., ve Mumford, M. D. (2007). Climate for Creativity: A Quantitative Review. Creativity Research Journal, 19(1),69-90.

Hussein, A. A., ve Wahba, K. (2003). The Readiness of IDSC to adopt knowledge management. (E. Coakes ed.), Knowledge Management: Current Issues and Challenges içinde (s. 239-262). London: IRM Press.

Janssen, O. (2000). Job demands, perceptions of effort-reward fairness and innovative work behaviour. Journal of Occupational and Organizational Psychology, 73(3), 287-302.

Kozlowski, S. W., ve Doherty, M. L. (1989). Integration of climate and leadership: Examination of a neglected issue. Journal of Applied Psychology, 74(4),546-553.

Messmann, G., ve Mulder, R. H. (2012). Development of a measurement instrument for innovative work behaviour as a dynamic and context-bound construct. Human Resource Development International, 15(1), 43-59.

Messmann, G., ve Mulder, R. H. (2017). Proactive employees: The relationship between work-related reflection and innovative work behaviour. (M. Goller, \& S. Paloniemi ed.) içinde, Agency at Work: An Agentic Perspective on Professional Learning and Development (s. 141-160). Switzerland: Springer.

Mumcu, A. (2018). Örgüt ikliminin örgütsel sinizm üzerindeki etkisinde izlenim yönetimi taktikleri ve lider-üye etkileşiminin aracılık rolü. Yayımlanmamış Doktora Tezi. Gaziosmanpaşa Üniversitesi Sosyal Bilimler Enstitüsü, Tokat. 
Mura, M., Lettieri, E., Radaelli, G., ve Spiller, N. (2013). Promoting professionals' innovative behaviour through knowledge sharing: The moderating role of social capital. Journal of Knowledge Management, 17(4), 527544.

Park, Y. K., Song, J. H., Yoon, S. W., ve Kim, J. (2014). Learning organization and innovative behavior: The mediating effect of work engagement. European Journal of Training and Development, 38(1/2),75-94.

Phung, V. D., Hawryszkiewycz, I., Chandran, D., ve Ha, B. M. (2017). Knowledge sharing and innovative work behaviour: A case study from Vietnam . Australasian Conference on Information Systems içinde (s. 1-11). Hobart: ACIS.

Radaelli, G., Lettieri, E., Mura, M., ve Spiller, N. (2014). Knowledge sharing and innovative work behaviour in healthcare: A micro-level investigation of direct and indirect effects. Creativity and Innovation Management, 23(4),400-414.

Ramamoorthy, N., Flood, P. C., Slattery, T., ve Sardessai, R. (2005). Determinants of innovative work behaviour: Development and test of an integrated model. Creativity and Innovation Management, 14(2),142-150.

Riege, A. (2005). Three-dozen knowledge-sharing barriers managers must consider. Journal of Knowledge Management, 9(3),18-35.

Ryu, S., Ho, S. H., ve Han, I. (2003). Knowledge sharing behavior of physicians in hospitals. Expert Systems with Applications , 25(1),113-122.

Sanders, K., \& Lin, C.-H. (2016). Human resource management and innovative behaviour: Considering Interactive, informal learning activities. (H. Shipton, P. Budhwar, P. Sparrow, \& A. Brown ed.) içinde, Human Resource Management, Innovation and Performance içinde (s. 32-47). New York: Palgrave Macmillan .

Schneider, B., Brief, A.,ve Guzzo, R. (1996). Creating a climate and culture for sustainable organizational change. Organizational Dynamics, 24(4),719.

Scott, S. G., ve Bruce, R. A. (1994). Determinants of innovative behavior: A path model of individual innovation in the workplace. The Academy of Management Journal, 37(3), 580-607.

Shih, H.-A., ve Susanto, E. (2011). Is innovative behavior really good for the firm?: Innovative work behavior, conflict with coworkers and turnover intention: moderating roles of perceived distributive fairness. International Journal of Conflict Management, 22(2),111-130. 
Stringer, R. (2001). Leadership and organizational climate. New York: Pearson.

Suliman, A. M. (2001). Are we ready to innovate? Work Climate-readiness to innovate relationship: The case of Jordan. Creativity and Innovation Management, 10(1),49-59.

Tiwana, A. (2000). The knowledge management toolkit: Practical techniques for building a knowledge management system. Upper Saddle River: Prentice Hall .

Tohidinia, Z., ve Mosakhani, M. (2010). Knowledge sharing behaviour and its predictors. Industrial Management \& Data Systems, 110(4),611-631.

Töre, E. (2017). Entelektüel sermayenin yenilikçi iş davranışına etkisinin bilgi paylaşımı, özyeterlilik ve iç denetim odağı perspektifinden incelenmesi üzerine bir araştırma. Yayımlanmamış doktora tezi. İstanbul Üniversitesi Sosyal Bïlimler Enstitüsü, İstanbul.

Tuncel, C. O., ve Bakir, H. (2010). Yenilik temelli bir bölgesel gelişme sürecinde kalkınma ajanslarının yeri. İşletme ve Ekonomi Araştırmaları Dergisi , 1(4),19-41.

Yuan, F., ve Woodman, R. W. (2010). Innovative behavior in the workplace: The role of performance and image outcome expectations. Academy of Management Journal, 53(2), 323-342.

\section{Kaynakça Bilgisi / Citation Information}

Yiğit, S. ve Yiğit, M. A. (2019). Örgüt iklimi algısı ve yenilikçi iş davranışı ilişkisinde bilgi paylaşımının aracılık rolü üzerine ampirik bir çalışma. OPUS-Uluslararası Toplum Araştırmaları Dergisi, 14(20), 182-206. DOI: $10.26466 /$ opus.594768 